\title{
Knowledge and Awareness Regarding Substance Addiction Among Medical Students of Valsad, Gujarat
}

\author{
Pragnesh Parmar* \\ Department of Forensic Medicine \& Toxicology, GMERS Medical College, India
}

*Corresponding author: Pragnesh Parmar, Associate Professor, Department of Forensic Medicine \& Toxicology, GMERS Medical College, Valsad, Gujarat, India

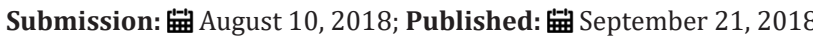

\begin{abstract}
Background: Substance addiction and problems arising out of it are changing from time to time and need to be updated in curriculum of medical students. Present study was aimed to analyze knowledge and awareness regarding substance addiction in medical students of Valsad District of Gujarat, India.

Materials and Methods: Total 135 medical students of $2^{\text {nd }}$ year MBBS were exposed to pre-tested and pre-validated Likert scale type questionnaire regarding knowledge and awareness of substance addiction after obtaining their informed written consent. Data obtained were analyzed via median score and tabulated.

Results: Most of the students had knowledge about drug addiction and habituation, physiological and psychological dependence due to drugs and various methods for addiction of various drugs. Medical students had poor knowledge and awareness regarding punishment for use of illegal drugs, deaddiction centre and its role in drug addictive patients and neither had they visited de-addiction centre ever. They had less knowledge regarding short term and long-term complications of drug abuse. Medical students had little knowledge about various drugs causing addiction and clinical features of various addictive drugs
\end{abstract}

Conclusion: Knowledge and awareness regarding substance addiction is found to be very poor among $2^{\text {nd }}$ MBBS students which can be overcome by educational programs like interactive lecture as well as visit to de-addiction centre.

Keywords: Addiction pattern; Medical students; Valsad; Gujarat; Knowledge; Awareness

\section{Introduction}

Drug abuse is mainly the result of interaction between person, abused drug, and the environment with changing patterns from time to time [1]. Knowledge and awareness regarding this giant problem and its effects are still less, easy access to drugs at certain places, other factors contribute in substance addiction [2]. The young generation usually involved in drug abuse because of lack of knowledge regarding its complications, peer pressure, influence by social media etc. [3]. The most prevalent used drugs were alcohol, opium, and marijuana till today [4]. Present study was undertaken to assess knowledge and awareness of medical students regarding substance addiction because they will serve key role in future by treating and counseling patients.

\section{Materials and Methods}

Total 135 medical students of $2^{\text {nd }}$ year MBBS were exposed to pre-tested and pre-validated Likert scale type questionnaire (Total 10 questions related to substance addiction with response ranging from Likert scale 1 to 7, 1 -Not at all true, 7 - Very true) regarding knowledge and awareness of substance addiction after obtaining their informed written consent.

\section{Inclusion criteria}

Those students of $2^{\text {nd }}$ year MBBS, GMERS Medical College, Valsad, Gujarat, India who wanted to participate voluntarily in this study were included.

\section{Exclusion criteria}

Those students who didn't want to participate were excluded. Study was started after obtaining ethical approval from the Institutional Ethical Committee. Data obtained were analyzed via median score and tabulated.

\section{Results}

Total 135 students were participated in the present study, out of which properly filled and responded 100 questionnaires were 
taken into consideration for data analysis while rest of improperly filled questionnaire were not taken into consideration. Out of 100 respondents, 55 were male and 45 were female. Most of the students had knowledge about drug addiction and habituation, physiological and psychological dependence due to drugs and various methods for addiction of various drugs. Medical students had poor knowledge and awareness regarding punishment for use of illegal drugs, de-addiction center and its role in drug addictive patients and neither had they visited de-addiction center ever. They had less knowledge regarding short term and long-term complications of drug abuse. Medical students had little knowledge about various drugs causing addiction and clinical features of various addictive drugs (Table 1). There was no statistically significant difference between perceptions of male and female as per Table 2 .

Table 1: Knowledge and awareness regarding addiction pattern among medical students (Likert scale: 1 to 7, 1 -Not at all true, 7 -Very true).

\begin{tabular}{|c|c|c|}
\hline Sr. No. & Perceptions of Students & Median Score \\
\hline 1 & I know about drug addiction and drug habituation. & 4 \\
\hline 2 & I am aware about various drugs causing addiction. & 3 \\
\hline 3 & I know about clinical features of various addictive drugs. & 3 \\
\hline 4 & I am aware about short term complications of drug abuse. & 2 \\
\hline 5 & I am aware about long term complications of drug abuse. & 2 \\
\hline 6 & I know about punishment for use of illegal drugs. & 1 \\
\hline 7 & I know about de-addiction centre and its role in drug addictive patients. & 5 \\
\hline 8 & I know about physiological and psychological dependence due to drugs. & 5 \\
\hline 9 & I am aware about various methods for addiction of various drugs. & \\
\hline 10 & I have visited de-addiction centre. & 1 \\
\hline
\end{tabular}

Table 2: Statistical analysis of gender-wise difference of perceptions.

\begin{tabular}{|c|c|c|c|c|c|c|c|c|c|c|}
\hline & Q1 & Q2 & Q3 & Q4 & Q5 & Q6 & Q7 & Q8 & Q9 & Q10 \\
\hline Mann-Whitney U & 1172.5 & 1166 & 995.5 & 1148 & 1211 & 1067 & 1207 & 926 & 1199 & 1050 \\
\hline Wilcoxon W & 2845.5 & 2132 & 2647 & 2092 & 2862 & 2718 & 2863 & 1892 & 2832 & 2016 \\
\hline Z & -0.345 & -0.388 & -1.75 & -0.63 & -0.12 & -1.366 & -0.131 & -2.385 & -0.381 & -1.239 \\
\hline Asymp. Sig. (2-tailed) & 0.73 & 0.699 & 0.08 & 0.528 & 0.901 & 0.173 & 0.896 & 0.016 & 0.703 & 0.209 \\
\hline
\end{tabular}

\section{Discussion}

Nowadays in India and neighboring countries, drug abuse and illicit drug trafficking are true challenges to society to combat with knowledge and awareness among general population [5]. Advancement of technology, development of toxicology laboratories and forensic department is very useful to detect drug crime. Methamphetamine, amphetamine, cocaine, and opiates are usually detected in forensic cases [6]. Some studies had thrown light over high correlation between adolescent abuse of drug which later becoming a bigger problem to drug user in adulthood [7]. Death related to drug abuse required thorough crime scene investigation to gather appropriate scientific evidence [8].

Different studies showed that drug abuse is affected by knowledge and attitude of person toward drugs. To change a behavior of person, at first knowledge and attitude towards that behavior should be corrected by proper representation of facts [9]. One study showed that religiosity seems to be perceived as a protective factor for substance use. Socio-demographic factors have an impact on attitudes and perceptions towards substance use [10]. In the Gulf countries drug use is described as "taboo" [11]. There is increasing literature on substance use and increased vulnerability to victimization $[12,13]$. On study emphasized the National Institute of Drug Abuse (NIDA) strategy of targeting modifiable risk factors and enhancing protective factors through family, school and community prevention programmes [14]. One study showed Level of knowledge on harmfulness of substance use among students was very high and they stated media as the most frequent source of information [15]. One Indian study showed that study material regarding substance abuse and their harmful effects can be imparted to teachers and later introduced in school curriculum [16].

\section{Conclusion}

Knowledge and awareness regarding substance addiction is found to be very poor among $2^{\text {nd }}$ MBBS students which in turn may lead to poor utilization of services provided at de-addiction centre as students play major role in counseling and spreading awareness. Educational programs like interactive lecture as well as visit to deaddiction centre should be required to increase knowledge and awareness among medical students.

\section{References}

1. Geramian N, Gharaat L, Taheri SA, Mohebpour F, Nahvizadeh M, et al. (2014) Development of a questionnaire to assess drug abuse among high school students of Isfahan province, Iran: An action research. Int J Prev Med 5(Suppl 2): S146-S153.

2. Donev GP, Kragelj LZ (2007) Health Promotion and Disease Prevention. Hans Jacobs Publishing Company, Lage, Germany. 
3. Parmar P, Rathod GB, Rathod S, Parikh (2015) A Drug abuse and illicit drug trafficking vis-à-vis human life-A review. Prensa Med Argent 101: 2

4. Farhadinasab A, Allahverdipour H, Bashirian S, Mahjoub H (2008) Lifetime pattern of substance abuse, parental support, religiosity, and locus of control in adolescent and young male users. Iran J Public Health 37(4): 88-95.

5. Parmar P, Rathod GB (2012) Explosion and explosives-a forensic review. International Journal of Current Research and Review 4(10): 33-38.

6. Parmar P, Rathod GB (2012) Forensic onychology: An essential entity against crime. J Indian Acad Forensic Med 34(4): 355-357.

7. Belcher HM, Shinitzky HE (1998) Substance abuse in children: prediction, protection, and prevention. Arch Pediatr Adolesc Med 152(10): 952-960.

8. Parmar P (2015) Reconstruction of crime-A review. IAIM 2(10): 49-53.

9. Sarami AA, Naderi H (2009) Comparison between participants and nonparticipants in terms of knowledge and attitude towards drug abuse. Humanity Soc Sci J 4: 76-82.

10. Elarabi H, Hamedi FA, Salas S, Wanigaratne S (2013) Rapid analysis of knowledge, attitudes and practices towards substance addiction across different target groups in Abu Dhabi city, United Arab Emirate. International Journal of Prevention and Treatment of Substance Use Disorders 1(1): 76-88.

11. Al Harthi A, Al Adawi S (2002) Enemy within? The silent epidemic of substance dependency in GCC countries. J Sci Res Med Sci 4(1-2): 1-7.

12. Kessler R, Sonnega A, Bromet E, Hughes M, Nelson C (1995) Posttraumatic stress disorder in the National Comorbidity Survey. Arch of Gen Psychiatry 52(12): 1048-1060.

13. Kilpatrick D, Acierno R, Resnick H, Saunders B, Best C (1997) A 2-year longitudinal analysis of the relationship between violent assault and substance use in women. J Consult Clin Psychol 65(5): 834-847.

14. Chakravarthy B, Shah S, Lotfipour S (2013) Adolescent drug abuse Awareness and Prevention. Indian J Med Res 137(6): 1021-1023.

15. Tsering D, Pal R, Dasgupta A (2010) Substance use among adolescent high school students in India: A survey of knowledge, attitude and opinion. J Pharm Bioallied Sci 2(2): 137-140.

16. Raphael L, Raveendran R, Sajna MV (2017) Prevalence and determinants of substance abuse among youth in Central Kerala, India. International Journal of Community Medicine and Public Health 4(3): 747-751.
Creative Commons Attribution 4.0

International License

For possible submissions Click Here

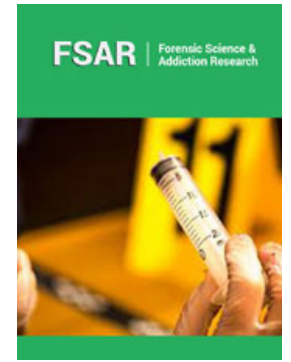

Forensic Science \& Addiction Research

\section{Benefits of Publishing with us}

- High-level peer review and editorial services

- Freely accessible online immediately upon publication

- Authors retain the copyright to their work

- Licensing it under a Creative Commons license

- Visibility through different online platforms 